\title{
HEXÁGONO SOCIOAMBIENTAL: UM JOGO DIDÁTICO DE EDUCAÇÃO AMBIENTAL NO CONTEXTO ESCOLAR
}

\author{
SOCIO-ENVIRONMENTAL HEXAGON: A DIDATIC GAME OF \\ ENVIORNMENTAL EDUCATION IN SCHOOLAR CONTEXT
}

\author{
Sirlei Aparecida de Lima Antoneli ${ }^{1}$ \\ Adriana Massaê Kataoka ${ }^{2}$ \\ Paulo Henrique Gonsalves ${ }^{3}$ \\ Juliana Mara Antonio ${ }^{4}$
}

\begin{abstract}
Resumo: O presente artigo buscou relatar a criação de uma ferramenta lúdica (jogo de tabuleiro) e avaliar a sua aplicabilidade voltada para inserção dos princípios de uma Educação Ambiental (EA) crítica no contexto escolar. Trata-se de uma pesquisa qualitativa, que foi realizada em uma escola no interior no Paraná, a pesquisa envolveu uma intervenção que consistiu na aplicação do jogo e posterior validação do mesmo. Participaram da aplicação 14 docentes da referida escola, desses apenas 8 participaram da validação da ferramenta pedagógica. A validação do jogo aconteceu por meio de dois questionários pós-intervenção. Para análise dos questionários, nos apoiamos na análise de conteúdo de Bardin (2004) e na escala Likert de Oliveira (2005). A avaliação do jogo pelos professores revelou que o mesmo é uma ótima ferramenta didática para trabalhar a EA na perspectiva crítica. Os resultados também revelaram que o mesmo potencializa o trabalho interdisciplinar, pois integrou aspectos históricos, sociais e econômicos envoltos nas problemáticas socioambientais, além de promover a interação entre os participantes, o interesse e a criatividade.
\end{abstract}

Palavras-chave: Atividade lúdica; Meio Ambiente; Educação Ambiental.

Abstract: This article sought to report the creation of a playful tool (board game) and to evaluate its
applicability aimed at inserting the principles of a critical Environmental Education (EA) in the school
context. It is a qualitative research, which was carried out in a school in the interior of Paraná, the research
involved an intervention that consisted of the application of the game and its subsequent validation. 14
teachers from that school participated in the application, of which only 8 participated in the validation of
the pedagogical tool. The game was validated using two post-intervention questionnaires. For the analysis
of the questionnaires, we rely on the content analysis of Bardin (2004) and the Likert de Oliveira scale

${ }^{1}$ Mestra em Ensino de Ciências e Matemática e licenciada em Ciências Biológicas pela Universidade Estadual do Centro-Oeste-UNICENTRO. Membro do Núcleo de Educação Ambiental do Departamento de Ciências Biológicas - UNICENTRO. R. Simeão Varela de Sá, 03 - Vila Carli, Guarapuava - PR, 85040080, Guarapuava, PR. E-mail: sirantoneli@yahoo.com.br

${ }^{2}$ Doutora e mestra em Ecologia e Recursos Naturais e licenciada em Ciências Biológicas pela Universidade Federal de São Carlos. Coordenadora do Núcleo de Educação Ambiental e docente do Departamento de Ciências Biológicas da Universidade Estadual do Centro-Oeste - UNICENTRO. R. Simeão Varela de Sá, 03 - Vila Carli, Guarapuava - PR, 85040-080, Guarapuava-PR. dri.kataoka@ hotmail.com

${ }^{3}$ Graduando em Física pela Universidade Estadual do Centro-Oeste-UNICENTRO e Ciência de Dados pela Universidade Cruzeiro do Sul. Membro do grupo de pesquisa Transporte em Sistemas Complexos UNICENTRO. Rua Simeão Varela de Sá, 03 - Vila Carli - 85040-080, Guarapuava - PR. paulo_henrique_rh@hotmail.com

${ }^{4}$ Mestra em Ensino de Ciências e Matemática e licenciada em Ciências Biológicas pela Universidade Estadual do Centro-Oeste-UNICENTRO. Pedagoga pela Universidade Cruzeiro do Sul. Membro do Núcleo de Educação Ambiental do Departamento de Ciências Biológicas - UNICENTRO. R. Simeão Varela de Sá, 03 - Vila Carli, Guarapuava - PR, 85040-080, Guarapuava, PR. julianamara85@ hotmail.com 


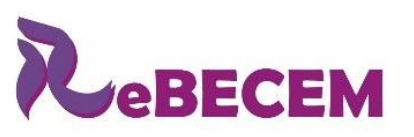

Revista Brasileira de Educação em

Ciências e Educação Matemática

DOI: https://doi.org/10.33238/ReBECEM.2020.v.4.n.2.24234

(2005). The evaluation of the game by the teachers revealed that it is a great didactic tool to work the EA in the critical perspective. The results also revealed that it enhances interdisciplinary work, as it integrated historical, social and economic aspects involved in socio-environmental issues, in addition to promoting interaction between participants, interest and creativity.

Keywords: Playful Activity; Envionment; Environmental Education.

\section{Introdução}

A Educação Ambiental (EA) é um campo que agrega diversas áreas do conhecimento, com a finalidade primordial de buscar a compreensão mais profunda dos problemas ambientais derivados da relação do ser humano (sociedade-natureza). A relação destrutiva do ser humano-natureza nas últimas décadas têm-se intensificado, provocando diversas crises, como a exploração dos recursos naturais e do trabalho humano, desigualdade social e conflitos socioambientais.

A EA considerada como campo do conhecimento atua de modo interdisciplinar em ambientes formais (escola e instituições de ensino) e informais (eventos culturais, sociais de modo geral) em ações de sensibilização da sociedade sobre as problemáticas socioambientais e maneiras de enfrentamento. Respaldando legislativamente, a EA baseia-se na Política Nacional de Educação Ambiental (PNEA) de 1999 e nas Diretrizes Curriculares Nacionais de Educação Ambiental (DCNEA) de 2012. A Lei nº 9.795/99, que institui a PNEA, no artigo 2 enfatiza o carácter essencial e permanente da EA, que deve ser incluída de modo interdisciplinar em todos os níveis e categorias da educação de maneira forma e informal.

Ainda existe uma enorme discrepância entre legislações e a realidade curricular das licenciaturas, de acordo com Gatti et al., (2008, p.118) "há crise na formação de docentes e, de certa forma, mobilizam na direção de uma atenção maior a cursos de licenciatura e a aspectos específicos da formação inicial". Desse modo, ao analisar a inclusão da EA no contexto escolar, Sepulcri e Tristão (2017) afirmam que a mesma não segue os princípios e normativas estipulados nas legislações como a condição integral, interdisciplinar e contínua, contrariando, evidencia-se práticas fragmentadas, pontuais e hierarquizadas. É como se a temática não tivesse relação com algumas disciplinas, sendo abordada frequentemente por docentes da disciplina de Geografia e Ciências.

Percebe-se, ainda, uma resistência e dificuldade em se trabalhar a EA sob uma perspectiva contextualizada e interdisciplinar, e este fato pode relacionar-se ao modo como o ensino é organizado, de maneira fragmentada, em que as disciplinas não se conectam. Outro fator é a possibilidade desses docentes não terem em sua formação 
DOI: https://doi.org/10.33238/ReBECEM.2020.v.4.n.2.24234

inicial subsídios que os amparassem no trabalho com essa temática, o que traz consequências em suas práticas escolares. Morin (2013, p.40) alerta que "a fronteira disciplinar, com sua linguagem e com os conceitos que lhe são próprios, isola a disciplina em relação às outras e em relação os problemas que ultrapassam as disciplinas”.

Sabendo-se da dificuldade de trabalhar de modo contextualizado e interdisciplinar, esse artigo pode contribuir com a prática docente, apresentando uma ferramenta didática associada à ludicidade, para trabalhar a Educação Ambiental (EA) de forma contextualizada e reflexiva. As atividades lúdicas têm se constituído como uma importante alternativa para superar dificuldade no ensino de EA, uma vez que auxiliam na motivação, integrando conhecimento e habilidades.

Assim, o presente artigo buscou relatar a criação de uma ferramenta lúdica e investigar a sua aplicabilidade voltada para inserção dos princípios de uma EA crítica no contexto escolar. A ferramenta refere-se a um jogo, com manual e regras, focalizando a temática ambiental, mais especificamente os resíduos sólidos. O jogo construído é composto por um tabuleiro, no formato hexagonal, subdividido em ambiente natural, rural e urbano. Esses ambientes foram escolhidos por apresentarem características próprias, evidenciando as interligações entre eles e diferentes graus de modificação impostas pelo ser humano. Também contém cartas envolvendo as problemáticas: crise hídrica, resíduos sólidos e agrotóxicos, situadas em seu contexto social, político e cultural, as quais foram aprofundadas e trazidas sob a perspectiva crítica.

Conforme Santaella (2012, p. 186), o lúdico demonstra nos jogos a expressão mais legítima de que "é o lugar no qual as forças da razão e da sensibilidade se fazem presentes”. Essa afirmação, segundo a autora, dá suporte teoricamente ao pensamento de diversos autores, ao indicar o expressivo potencial dos jogos para o desenvolvimento de habilidades cognitivas e socioafetivas. Tal potencial baseia-se no fato do jogo derivar da conexão dos impulsos do ser humano (o sensório, racional e sensível) que, apenas ao se entrelaçarem, o tornam plenamente humano, como evidenciado pelo filósofo Schiller (1994).

É importante destacar que a presente pesquisa é resultado da dissertação de mestrado de uma das autoras, realizada no Programa de Mestrado Profissional em Ensino de Ciências Naturais e Matemática da Universidade Estadual do Centro-Oeste (UNICENTRO). Este artigo apresenta inicialmente os princípios da educação ambiental e sua relação com as atividades lúdicas, para posteriormente descrever o percurso metodológico da pesquisa e aspectos referentes à criação, descrição e aplicação do jogo 


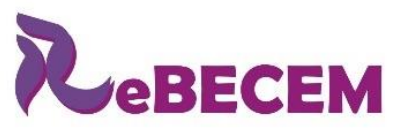

DOI: https://doi.org/10.33238/ReBECEM.2020.v.4.n.2.24234
Revista Brasileira de Educação em

Ciências e Educação Matemática

ISSN 2594-9179

e finaliza trazendo a avaliação do mesmo por professores de uma escola do interior do Paraná.

\section{Atividades lúdicas em Educação Ambiental}

As distintas formas de impactos ambientais (desmatamento, queimadas, alta produção de resíduos sólidos tóxicos, poluição do ar, solo, água) ocorrem, fundamentalmente, devido ao tipo de relação que o ser humano institui com o ambiente. No processo de sua evolução, o ser humano desenvolveu-se social e culturalmente, formando diversos modos de interferir no meio natural, ocasionando geralmente muita destruição ambiental. De tal modo, é imprescindível expandir a percepção ambiental, objetivando a restituição da relação sociedade e ambiente, a partir de uma perspectiva crítica das relações socioambientais, repensando e reelaborando novas formas de convívio e de atuação no meio (OLIVEIRA; VARGAS, 2009).

Para Carvalho (2008), a EA pode contribuir nessa ampliação de percepção, na formação de sujeitos com capacidade de compreender e agir no mundo de maneira crítica, participando dessa intencionalidade educativa, em que se lê e interpreta o mundo em constante mudança.

Assim, ao analisar como o campo da Educação Ambiental é caracterizado, observa-se que existem distintos modos de concepção e prática educativa. Essas concepções distintas podem sofrer influência da educação, da formação, da política, da cultura, entre outros fatores. Por conseguinte, por ser trabalhada de muitas maneiras e por distintas áreas do conhecimento, pode ser tratada de modo genérico, com conceitos superficiais e práticas sem fundamentos e reflexões. Em contrapartida, o agir de forma conectada e dialogada pode enfim alcançar a finalidade da EA, que é compreensão da profunda relação do ser humano-natureza, para posterior transformação significativa dessa relação sociedade-natureza (menos destrutiva e mais equilibrada).

Conforme a maneira que a EA é praticada e a visão de meio ambiente empregada, ela é classificada de acordo com Layrargues e Lima (2011) em três principais macrotendências: conservadora, pragmática e crítica, sendo essa uma das classificações dentre outras existentes. A macrotendência conservadora, que se origina dos conceitos da ecologia, enfatiza a afetividade perante a natureza, focalizando na transformação individual por meio de adestramentos sem reflexões. A pragmática possui como foco a praticidade, ou seja, procura de modo prático resolver um problema ambiental sem refletir 


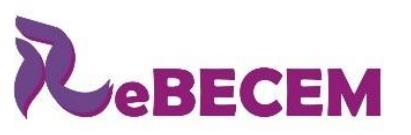

Revista Brasileira de Educação em

Ciências e Educação Matemática

DOI: https://doi.org/10.33238/ReBECEM.2020.v.4.n.2.24234

ou procurar entender a problemática, como por exemplo, para o aumento de resíduos sólidos na visão pragmática, apenas a coleta seletiva seria o ideal. A macrotendência crítica tem como finalidade a superação da falta de contextualização e politização do debate ambiental, traz as diferentes dimensões do ambiente (biológico, físico, político, cultural, econômico) e problematiza as incoerências dos padrões de desenvolvimentos.

Embora a EA tenha iniciado no Brasil com a vertente conservadora, ou seja, limitando-se a uma concepção de meio ambiente estritamente como natureza, ao reconhecer-se no campo da educação, passou a incorporar aspectos sociais ao ambiente. Desde então, as pesquisas nesse campo fundamentaram-se em teorias já consolidadas e amplamente conhecidas da educação como a Fenomenologia, Hermenêutica e a Crítica (KATAOKA; ANTONIO; NEUMAN, 2018). Desse modo, a partir de então, como campo educacional social, buscam-se estratégias para aproximar o ensino da educação ambiental e a produção de ferramentas didáticas que contribuam com a finalidade da EA nas perspectivas recomendadas pelas legislações (crítica, interdisciplinar e contínua).

A interdisciplinariedade é um fundamento relevante na EA crítica, a interdisciplinariedade não tem como pretensão a unificação do conhecimento, no entanto, almeja a abertura de espaço para a articulação de saberes. Nesse contexto, as disciplinas se encontram em recíproca cooperação, elaborando, assim, um referencial metodológico e conceitual comum para o entendimento de contextos complexos. Tem também a transdisciplinaridade, que vai além da interdisciplinariedade e rompe às fronteiras das disciplinas, desse modo, cada conhecimento especializado seria fundindo em um saber mais amplo (CARVALHO, 2008).

Para materializar uma abordagem dinâmica dos princípios da EA, incluindo a interdisciplinariedade, as atividades lúdicas podem ser uma proposta interessante, uma vez que ajudam a desenvolver a criatividade e a participação, levando a compreensão das problemáticas socioambientais e a transformação das relações entre sociedade e natureza.

Para incentivar maior inclusão e entendimento dos indivíduos em relação ao compromisso socioambiental, uma opção seria desenvolver recursos didáticos alternativos como jogos e atividades lúdicas que estimulem o desenvolvimento do indivíduo, e consequente transformação da comunidade e do meio ambiente. $O$ desenvolvimento do educando é fundamental para que ele atue na sociedade, compreendendo seus aspectos sociais, culturais e políticos, possibilitando melhorar seu entendimento e mudanças de concepções (JACOBI, 2003). 


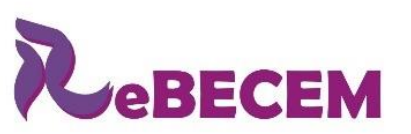

Revista Brasileira de Educação em

Ciências e Educação Matemática

DOI: https://doi.org/10.33238/ReBECEM.2020.v.4.n.2.24234

Em seu estudo, Cordazzo e Vieira (2007) explicam algumas diferenças entre ações lúdicas e jogos, sendo consideradas ações lúdicas as brincadeiras, aquela que tem um aspecto livre, não organizada e representativa e o jogo como aquele que possui uma organização prática, com regras pré-estabelecidas e relacionadas com aspectos sociais, morais e culturais que fazem parte da vivência do indivíduo.

Dando enfoque aos jogos, Kishimoto (1996, p.37) diz que "a utilização do jogo potencializa a exploração e a construção do conhecimento, por contar com a motivação interna típica do lúdico". O jogo consiste em parte da natureza humana, seja na fase inicial ou adulta, sendo um instrumento de grande valor integrador, pois proporciona a oportunidade das pessoas encontrarem-se, conhecerem o outro e o mundo. Conforme Kishimoto (1996), o jogo na educação promove o equilíbrio entre a função lúdica (propicia diversão e prazer) e a função educativa (desenvolvimento afetivo, motor, cognitivo, social e moral), conectando essas duas funções para uma aprendizagem significativa. Assim, o jogo tem a função de facilitador do ensino e aprendizagem, levando o aluno a pensar, raciocinar, analisar e compreender melhor os processos cognitivos. Como falam Rizzi e Haydt (2001):

Nos jogos de regra, os jogadores estão, não apenas um do lado do outro, mais
junto. (...) o conteúdo e a dinâmica do jogo não determinam apenas a relação
da criança com o objeto, mas também suas relações em face a outros
participantes do jogo. (...) Assim, o jogo de regras possibilita o
desenvolvimento das relações sociais da criança (RIZZI; HAYDT, 2001, p.86).

Nessa perspectiva, cada vez mais a utilização dos jogos didáticos tem completado lacunas no campo educacional, pela sua capacidade de estimular o lado emocionalsentimental dos envolvidos, proporcionando aos jogadores entusiasmo e criticidade (GOMES; FRIEDRICH, 2001). Por esses e outros motivos, os jogos têm sido utilizados com a intenção de melhorar o desempenho escolar dos alunos, o desenvolvimento do processo do ensino-aprendizagem, como também, a racionalidade, a integração destes na sociedade, o encorajamento, entusiasmo e a imaginação (RIEDER et al., 2004).

Para que os jogos entrem na agenda dos professores, Santos (1997) sugeriu o trabalho com o lúdico nos cursos de formação de professores. Essa dimensão é, segundo a autora, componente essencial para que o professor possa integrar uma dimensão lúdicopedagógica a sua prática. A mesma autora diz que, quanto mais o adulto experimentar sua ludicidade, melhor será a oportunidade desse profissional trabalhar com a criança de forma agradável. Ainda afirma que a formação lúdica proporciona ao educador distinguir- 
DOI: https://doi.org/10.33238/ReBECEM.2020.v.4.n.2.24234

se como pessoa, ser capaz de enxergar outras perspectivas, ter uma concepção clara sobre a importância do jogo e do brinquedo para a vida da criança, do jovem e do adulto.

Dessa forma, faz-se necessário ensinar e sensibilizar o professor-aprendiz para que, por meio de atividades lúdicas, desperte no sujeito-aprendiz o prazer e o interesse pelo estudo. O professor deve preparar suas atividades e determinar suas finalidades, considerando que os estudantes têm aspirações, estímulos, convicções e argumentos que devem ser considerados pelo professor. Neste viés, e pensando o jogo não apenas como diversão, mas como construção coletiva do conhecimento, que se dá no processo de interação e aproximação com a realidade do estudante foi elaborado a ferramenta didática descrita a seguir.

\section{Percurso metodológico}

Trata-se de uma pesquisa qualitativa, que foi realizada em uma escola estadual no interior no Paraná, a pesquisa envolveu uma intervenção que consistiu na aplicação do jogo e posterior validação do mesmo. Participaram da pesquisa 14 docentes dessa escola. $\mathrm{Na}$ Tabela 1 estão os professores e sua área de formação.

Tabela 1: Área de atuação e formação dos participantes da pesquisa

\begin{tabular}{ccc}
\hline Participantes & Quantidade & Formação \\
\hline A1, A2, A3. & 3 & Matemática \\
B1, B2. & 2 & Português \\
C1. & 1 & Sociologia \\
D1 & 1 & Geografia \\
E1 & 1 & Física \\
F1 & 1 & História \\
G1 & 1 & Química \\
H1 & 1 & Inglês \\
I1 & 1 & Ed. Física \\
J1 & 1 & Geografia/História \\
K1 & 1 & Geografia/Ensino Religioso \\
\hline
\end{tabular}

Fonte: Autores (2018)

O referido Jogo foi apresentado aos professores e posteriormente, os mesmos tiveram a oportunidade de jogá-lo. Após a sua aplicação os professores foram convidados a realizar a validação do jogo.

\subsection{Avaliação e validação do jogo}

A validação do jogo aconteceu por meio de dois questionários pós-intervenção. Sendo que um deles envolveu a avaliação relacionada à aplicabilidade da ferramenta 


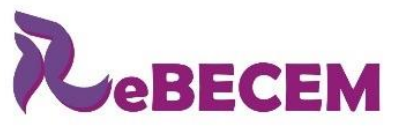

Revista Brasileira de Educação em
Ciências e Educação Matemática

DOI: https://doi.org/10.33238/ReBECEM.2020.v.4.n.2.24234

didática (jogo) e outro sobre a temática ambiental e questões gerais acerca da ferramenta didática analisada. Os questionários são compostos por questões abertas, nas quais o respondente tem uma maior liberdade de escrever suas respostas. O primeiro questionário foi composto por um total de cinco perguntas. Segue as perguntas:

1- Após as intervenções você mudaria a forma como vem trabalhando a temática ambiental? Justifique

2- Sobre seus conceitos de Meio ambiente e Educação Ambiental, você teve alguma mudança? Explique.

3- Quanto à aplicabilidade do jogo. Você usaria em suas aulas? Em caso negativo por quê?

4- Aspectos positivos e negativos do jogo.

5- Você teria sugestões para melhorar esse jogo.

Cabe destacar que para a construção desse artigo, devido a limitação de páginas optou-se por analisar apenas a questão 4 que se refere aos aspectos positivos e negativos da ferramenta pedagógica. Para análise do primeiro questionário, utilizou-se a análise de conteúdo de Bardin (2004), tendo como etapas 1) pré-análise, 2) exploração do material e 3) tratamento dos resultados, inferência e interpretação.

Os resultados foram organizados em duas categorias pré-estabelecidas: aspectos positivos e aspectos negativos da ferramenta didática. Cada uma delas foi subdividida em subcategorias que emergiram das respostas. A categoria "aspectos positivos" foi subdividida nas subcategorias: promove interações, instiga raciocínio e desperta interação. Já a categoria "aspectos negativos”, foi subdivida nas subcategorias: tabuleiro pesado e tempo de duração do jogo. As categorias emergiram dos dados coletados através do questionário (instrumento de coleta).

O questionário 2 refere-se à aplicabilidade da ferramenta, esse questionário foi respondido por 8 professores, esse fato se explica pela necessidade de alguns professores terem que se retirar nessa etapa da intervenção. Contêm nove afirmativas, os participantes foram convidados a emitir o seu grau de concordância sobre as seguintes afirmativas:

1- O jogo apresenta regras claras.

2- É possível ensinar EA, utilizando o jogo didático.

3- Quanto à aplicabilidade do material didático. Você usaria em suas aulas.

4- O jogo promove a cooperaçãoentre os alunos.

5- O jogo desperta o interesse dos alunos.

6- O jogo instiga a criticidade dos alunos. 


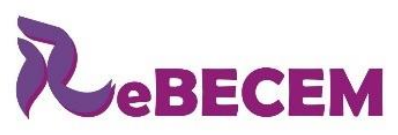

Revista Brasileira de Educação em

Ciências e Educação Matemática

DOI: https://doi.org/10.33238/ReBECEM.2020.v.4.n.2.24234

7- Você prefere trabalhar EA de forma tradicional (slides, quadro, livros).

8- Você considera o jogoatrativo.

9- Você já utilizou outros jogos didáticos.

A análise do segundo questionário baseia-se na escala de Likert. Esta escala pode ser usada para estimar a motivação no aprendizado e a concordância sobre uma afirmação. Segundo Costa (2009), a vantagem dessa escala é que ela facilita ao pesquisador emitir com confiabilidade o grau de satisfação sobre o tema, no caso o jogo. De acordo com Mattar (2001), para cada item de resposta apresentada no questionário na escala Likert é atribuído um número que representa a direção dos participantes em relação à afirmação. Em cada questão, calculou-se o Ranking Médio (RM), o qual permite mensurar o grau de concordância dos participantes, conforme Oliveira (2005), utilizando uma escala de 1 a 5.

Para interpretar os resultados do RM, utilizou-se a seguinte quantificação: valores iguais a 3 foram considerados neutros, valores acima de 3, concordantes e abaixo de 3 , discordantes. A questão 7 é inversa ao comparado aos demais, por isso, para essa questão, valores acima de 3 são discordantes e abaixo de 3, concordantes.

Desse modo, o primeiro questionário pós-intervenção com os professores participantes da pesquisa, buscou identificar as potencialidades e limites do jogo visando sua otimização (pontos positivos e negativos). Para atender os critérios de validação, os docentes responderam ao segundo questionário relativo ao funcionamento e metodologia do jogo.

\section{Resultados}

Os resultados e discussões estão organizados em três partes, a primeira está relacionada aos aspectos relacionados à criação do jogo e sua descrição, a segunda parte dos resultados é referente à validação do jogo, que foi subdivida em avaliação quanto aplicabilidade e aspectos positivos e negativos da ferramenta didática e avaliação relacionada à jogabilidade.

\subsection{Aspectos relacionados à criação do jogo e sua descrição}

O jogo "Hexágono socioambiental" foi desenvolvido procurando demonstrar as interligações entre o ambiente natural, urbano e rural, além de envolver as problemáticas crises hídrica, resíduos sólidos e agrotóxicos, trazendo-as sob a perspectiva crítica. 


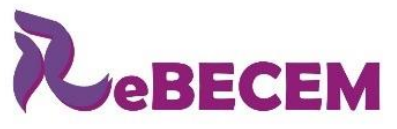

\section{Revista Brasileira de Educação em \\ Ciências e Educação Matemática}

DOI: https://doi.org/10.33238/ReBECEM.2020.v.4.n.2.24234

O tabuleiro tem o formato hexagonal com seis ambientes, sendo eles igualmente divididos para o ambiente urbano, rural e natural. Pode ser jogado por seis jogadores (individual) ou em equipe. Esse tabuleiro foi confeccionado em madeira, com duas gavetas para guardar materiais, entretanto, também foi construído protótipos com materiais de baixo custo e de fácil acessibilidade, como o papelão.

\section{Figura 1: Modelo do jogo Hexágono socioambiental}

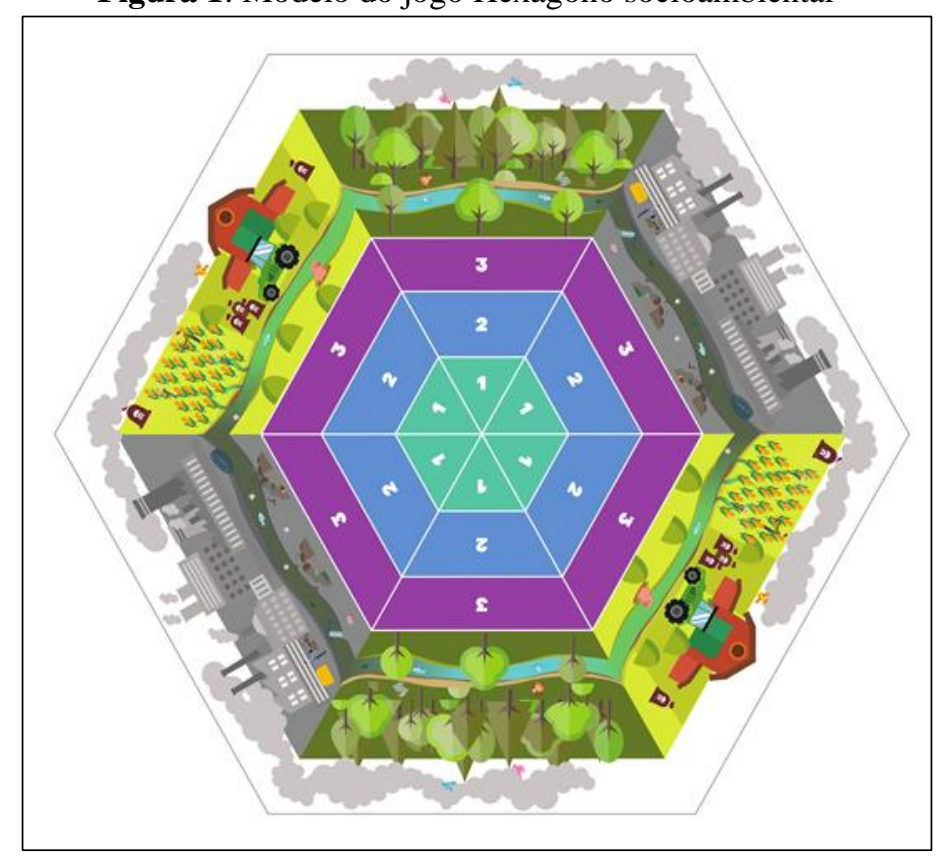

Fonte: Autores (2018)

O design traz informações sobre problemáticas ambientais, sendo ela: resíduos sólidos, crise hídrica e agrotóxicos (problemáticas mais citadas pelos professores na escola em que a pesquisa foi realizada). Os desenhos representam as interligações presentes entre os ambientes natural, rural e urbano, em que um interfere no outro de modo inter-relacional. No centro traz uma roleta também com seis pistas (uma para cada ambiente), numerada de um a três, que pode ser rotacionada tanto para a direita quanto para a esquerda. O jogador sai da casa número um e a cada resposta certa evolui uma casa. O desafio é responder três questões de maneira crítica sobre cada ambiente e ao responder de maneira adequada, o participante obtém um título que representa certo domínio de conhecimento sobre o ambiente.

Além dos fatores intelectuais, o jogo desenvolvido preza pelo uso de estratégias e da interatividade entre jogadores para suas relações in-game de maneira em que é possível trabalhar cooperativamente com seus "adversários" ou atrasando o avanço deles (ambas mecânicas de jogo possuem suas regras descritas no manual). Ele pode ser jogado por 
DOI: https://doi.org/10.33238/ReBECEM.2020.v.4.n.2.24234

alunos do Ensino Médio ou ainda pode ser adaptado para a faixa etária que desejar, pois apesar das mecânicas de jogo diferentes, a simplicidade e facilidade de aprendizado são aspectos fundamentais da estrutura do jogo. Mais do que isso, o jogo pode ainda ser aplicado visando à interdisciplinaridade, vinculando-se com diferentes disciplinas e assuntos.

As formas possíveis de se jogar são individualmente ou em equipes, com a duração de 1 hora aula, sendo a presença do professor fundamental, como mediador, com auxílio do manual (o qual traz possíveis respostas, bem como o guia para eventuais dúvidas a respeito das regras e dinâmicas). O jogo pode ser encerrado de duas maneiras: i) quando um participante ou equipe conseguir três cartas-títulos, uma do ambiente urbano, uma do ambiente natural e uma do ambiente rural; ii) ou terminar em um determinado tempo aonde o vencedor é determinado pelo participante que tem maior número de cartas-títulos.

O jogo contém 33 cartões-perguntas, sendo 11 de cada ambiente (natural, urbano e rural), com perguntas contextualizadas referentes à crise hídrica, resíduos sólidos e agrotóxicos (Figura 2). Nove cartas são intituladas de cartas-título, o participante ganha uma carta cada vez que passa por um ambiente, ou seja, ao responder três perguntas adequadamente, e nove cartas bônus que permitem uma rotação na roleta ou uma aliança com um participante ou outra equipe. Ainda tem nove cartas extras (apenas com capa, em branco) para serem usadas nas alianças, uma vez que quando acertam, os dois participantes avançam e ganham uma carta dentro do seu ambiente (estando então mais próximos de receber a carta-título) ou para o professor poder usar para criar outras questões atuais, que poderão substituir as que ficam ultrapassadas, visto que as problemáticas referem-se a problemas atuais. 
DOI: https://doi.org/10.33238/ReBECEM.2020.v.4.n.2.24234

Figura 2: Demonstração de Cartas ambiente, cartas bônus e cartas título

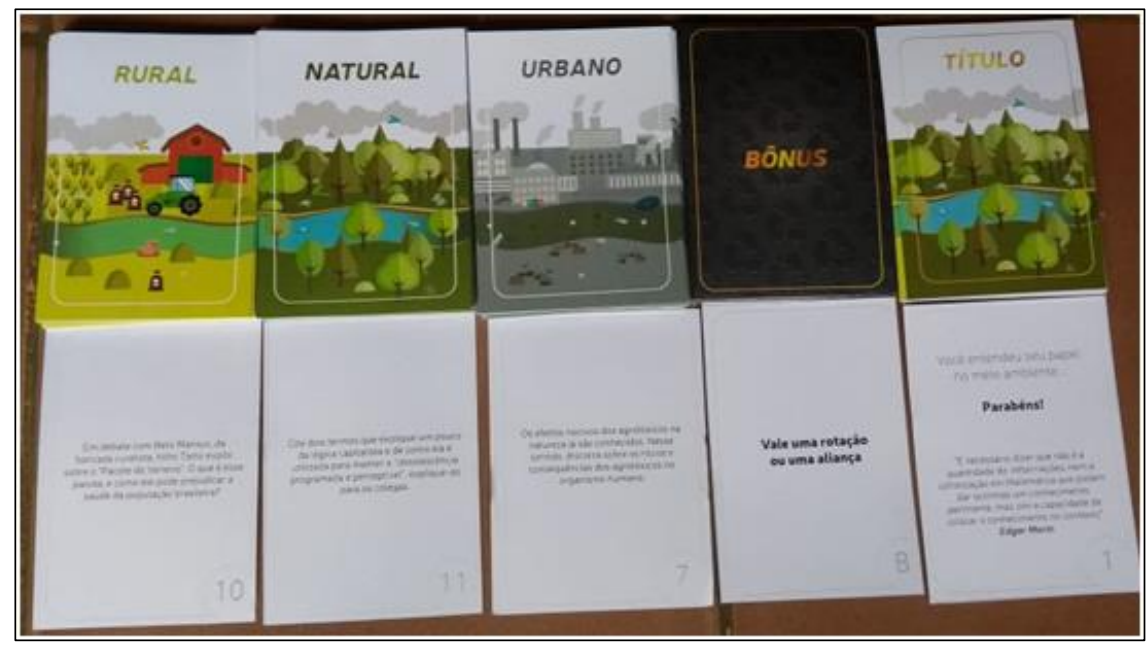

Fonte: Antoneli (2018)

Necessitam seis peões ou de quantos jogadores estiverem jogando. Os peões poderão ser confeccionados ou utilizar seis marcadores qualquer, exemplo peões do jogo de xadrez.

Dado de seis faces será usado para ver a ordem que irão jogar, sortear o tipo de ambiente e para rotacionar a roleta. $\mathrm{O}$ mesmo pode ser comprado em papelarias ou, então, pode ser confeccionado com a impressão de um modelo prévio.

\section{Validação}

\subsection{Avaliação quanto aplicabilidade e aspectos positivos e negativos}

Os professores foram questionados quanto à aplicabilidade do jogo de EA, ou seja, se eles usariam o jogo em suas aulas. Não obstante, também foram questionados sobre os aspectos positivos e negativos do jogo, onde deveriam destacar as potencialidades e as falhas.

Em relação à aplicabilidade da ferramenta didática de EA (jogo), todos os professores participantes afirmaram que usariam o jogo em suas aulas, afirmando que por meio dele facilitaria a compreensão, despertaria a curiosidade e, ainda, que poderia auxiliar no desenvolvimento da EA crítica. Isso pode ser observado nas falas do professor $\mathrm{EF} 1$ e $\mathrm{H} 1$ respectivamente:

EF1- Com certeza, a questão da competição poderia ser explorada para aumentar os conhecimentos sobre EA.

H1- Com certeza usaria, pois o mesmo auxiliam o desenvolvimento da educação crítica em relação ao meio ambiente. 


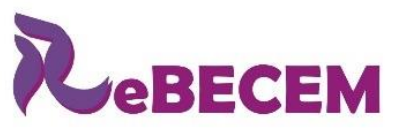

\section{Revista Brasileira de Educação em \\ Ciências e Educação Matemática}

DOI: https://doi.org/10.33238/ReBECEM.2020.v.4.n.2.24234

Os professores demonstraram grande interesse em jogar, interagindo entre si e aparentemente se divertindo. Eles demonstraram certo domínio dos conteúdos abordados pelo jogo e poucas dificuldades em avançar pelo tabuleiro. Durante o jogo, os professores foram divididos em grupos e orientados pelo mediador, que estimulava as reflexões em relação a possível resposta e respondendo possíveis questionamentos dos mesmos sobre as regras do jogo e dúvidas sobre as questões.

No decorrer do jogo, foi possível notar que a interação dos professores foi muito satisfatória, alguns até ajudavam seus colegas a pensarem e responderem as questões, demonstrando que se pode trabalhar coletivamente. Também foi possível notar que o jogo propiciou a união, a solidariedade e o avanço no conhecimento por meio das interações.

Consideramos que o jogo possui potencial para estimular a prática interdisciplinar, que pode ser capaz de evoluir para uma prática transdisciplinar, como propõe Suanno (2010), quando diz que a prática transdisciplinar leva a uma abertura de tolerância, com propósito do ético pelo bem comum, isso inclui valores e compreensão que vão além do racional, essa prática exige sensibilidade, sentimento, tolerância para então resultar em sabedoria.

As questões do jogo envolveram as problemáticas de forma contextualizada, em diferentes ambientes e dimensões. Conforme Morin (1997), essa compreensão do mundo está de acordo com o princípio sistêmico-organizacional que explica que um sistema é uma unidade global organizada por inter-relações. Portanto, necessita de compreensão do todo que o constitui, onde é preciso conhecer as relações todo/partes. Essas contextualizações puderam trazer a temática ambiental para a sala de aula, oportunizando a reflexão.

Diante dessas percepções, Batalloso (2012) afirma que é indispensável o papel da educação como facilitadora e promotora de desenvolvimento da consciência, da vontade, da compreensão e do compromisso, como dimensões estratégicas da aprendizagem e do ensino da condição humana. Considerando que os problemas mais importantes da vida são sempre globais, contextuais e relacionais, sendo preciso buscar e encontrar estratégias que permitam contextualizar, relacionar, conectar e religar saberes, conhecimentos e disciplinas.

Por último, foi realizada a avaliação do material didático de EA pelos participantes. Todos citaram pelo menos algum ponto positivo e apenas dois aspectos negativos em relação ao material didático de EA, como demonstra a Tabela 2. 
DOI: https://doi.org/10.33238/ReBECEM.2020.v.4.n.2.24234

Tabela 2: Aspectos positivos e negativos do jogo, segundo os professores

\begin{tabular}{ccc}
\hline Categorias & Descrição & Frequência absoluta \\
\hline \multirow{3}{*}{ Positivos } & Promove interações & 4 \\
& Instiga o raciocínio & 3 \\
\multirow{2}{*}{ Negativos } & Desperta o interesse & 2 \\
& Material pesado para a confecção do tabuleiro & 1 \\
\hline
\end{tabular}

Fonte: Autores (2018)

Os principais pontos positivos citados foram à interação entre os participantes (4 participantes), referindo-se à ampliação do conhecimento em relação às problemáticas ambientais pelas interações e reflexões notada nas respostas de alguns professores:

EF1 - Promove a reflexão acerca de assuntos do cotidiano dos alunos e principalmente a interação e troca de ideias entre eles e com o monitor.

GH1 - Integração dos alunos, trabalho em grupo, conscientização, aprendizado de uma forma divertida.

Outro ponto positivo citado foi que estimula o raciocínio (3), ampliando o conhecimento acerca das problemáticas, conforme fala do professor: Q1- "O jogo instiga o raciocínio, o conhecimento crítico e atualização acerca das problemáticas ambientais".

E ainda, alguns salientaram que o jogo incentiva a participação (2) e desperta o interesse pela temática, percebida nas respostas dadas: I1 - "Desperta o interesse por ser trabalhado o tema de maneira diferente do habitual"; e M3 - "Jogo muito instrutivo, prático, criativo que com certeza desperta o gosto em aprender do aluno".

Os discursos dos professores revelaram que essa ferramenta metodológica promove reflexões e melhor entendimento sobre EA, uma vez que proporciona integração entre os participantes, ajuda no raciocínio e na motivação. Neste sentido, Rizzi e Haldt (2007, p. 15) enfatizam que:

O jogo supõe relação social, supõe interação, por isso, a participação em jogos contribui para a formação de atitudes sociais: respeito mútuo, solidariedade, cooperação, obediência às regras, senso de responsabilidade, iniciativa pessoal e grupal. É jogando que a criança aprende o valor do grupo (RIZZI; HALDT, 2007, p. 15).

Quanto aos pontos negativos, a maioria não constatou, mas alguns mencionaram: utilizar material reciclável e mais leve na confecção do tabuleiro e falta de tempo para jogo, devido à quantidade de conteúdos que tem para trabalhar dentro da disciplina.

Os resultados indicaram que o jogo teve uma avaliação positiva na aceitação e satisfação, sendo uma proposta inovadora, dinâmica e criativa para se trabalhar a EA, pois permite que sejam trabalhados não apenas questões ambientais, mas questões sociais, éticas, políticas, econômicas e culturais, sendo uma ferramenta de motivação e aprendizagem. 


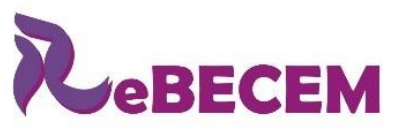

Revista Brasileira de Educação em

Ciências e Educação Matemática

DOI: https://doi.org/10.33238/ReBECEM.2020.v.4.n.2.24234

Para finalizar, os professores foram questionados se teriam alguma sugestão para melhorar o jogo. As sugestões foram de grande valia, sendo os aspectos relacionados à visibilidade do jogo a mais citada. O tabuleiro fica exposto em plano reto, sugestão para que fosse fixado junto à lousa, proporcionando maior visibilidade. Visto nas falas dos professores:

S1 - Desenvolver em outro material para que pudesse ser exposto junto ao quadro negro; trazer problemas/perguntas referentes ao município do aluno. Q1 - Questão de visibilidade do jogo, talvez em forma de roleta, para pendurar no quadro, estar sempre atualizando as questões.

Além de maior visibilidade, o material produzido em maior extensão e exposto no quadro fica acessível ao professor, que não precisará elaborar muitos materiais, sendo apenas necessário um deles para se trabalhar com uma turma inteira, o que por sua vez ajuda na indisciplina porque todos precisam estar atentos ao professor e ao seu grupo para ter melhor desempenho no jogo. Outra sugestão importante foi à utilização de um material mais leve, o que já havia sido usado no protótipo (papelão): P1 - “[...] material mais leve; algo mais prático". Isso também contribui para a acessibilidade do material, tanto do ponto de vista de facilitar o transporte, como para a aquisição, pois tem um custo mais acessível.

Diante das sugestões dos professores, foi desenvolvido um modelo para ser confeccionado no papelão, com design para ser impresso em folha A4, bem como, cartas e regras confeccionadas para impressão em folha A4. Assim, o professor que desejar poderá imprimir e montar seu próprio jogo. As perguntas podem ser adequadas ao contexto socioeconômico e cultural de cada realidade. O modelo encontra-se disponível no site do Programa de Pós-Graduação em Ensino de Ciências Naturais e Matemática da Universidade Estadual do Centro-Oeste na aba de produtos educacionais, disponível no link: http://tede.unicentro.br:8080/jspui/handle/jspui/1050.

\section{Avaliação relacionada à jogabilidade}

Os dados obtidos no questionário sobre a funcionalidade e metodologia do jogo seguem na Tabela 3.

Tabela 3: Dados obtidos no questionário respondido pelos 9 professores, sobre a funcionalidade e

\begin{tabular}{cccccccccc}
\multicolumn{10}{c}{ metodologia do jogo } \\
\hline Afirmativas & P1 & P2 & P3 & P4 & P5 & P6 & P7 & P8 & RM \\
1. O jogo apresenta regras claras. & 5 & 5 & 5 & 5 & 5 & 5 & 5 & 5 & 5 \\
$\begin{array}{c}\text { É possível ensinar EA, utilizando o } \\
\text { jogo didático. }\end{array}$ & 5 & 5 & 5 & 5 & 5 & 5 & 5 & 5 & 5. \\
\hline
\end{tabular}


DOI: https://doi.org/10.33238/ReBECEM.2020.v.4.n.2.24234

Quanto à aplicabilidade do material didático. Você usaria em suas aulas.

O jogo promove a cooperaçãoentre os alunos.

5. O jogo desperta o interesse dos alunos.

6. O jogo instiga a criticidade dos alunos.

Você prefere trabalhar EA de forma tradicional (slides, quadro, livros).

8. Você considera o jogoatrativo.

9. Você já utilizou outros jogos didáticos.

\begin{tabular}{ccccccccc}
5 & 5 & 5 & 5 & 5 & 5 & 5 & 5 & 5 \\
5 & 5 & 5 & 5 & 5 & 5 & 5 & 5 & 5 \\
5 & 5 & 5 & 5 & 5 & 5 & 5 & 4 & 4,875 \\
5 & 5 & 5 & 5 & 5 & 5 & 5 & 5 & 5 \\
1 & 1 & 1 & 1 & 1 & 3 & 1 & 1 & 1,25 \\
5 & 5 & 5 & 5 & 5 & 5 & 5 & 5 & 5 \\
5 & 3 & 3 & 1 & 5 & 1 & 1 & 1 & 2,5 \\
\hline
\end{tabular}

Fonte: Autores (2018)

De acordo com o RM, todos os participantes concordam que o jogo apresenta regras claras, bem como, é um jogo possível de aplicar e ensinar a temática ambiental. A maioria dos professores concordam que o jogo promove a cooperação entre os alunos, bem como, os instiga à criticidade e desperta o interesse. Quando questionados sobre a forma de trabalhar a EA, a maioria dos participantes concordou que jogo é mais atrativo que o método tradicional, mas mesmo assim poucos professores tiveram contato com jogos didáticos antes dessa experiência.

Também é importante destacar, a escassez de trabalhos que relacionem jogos com uma faixa etária mais elevada. O que pode ser visto na pesquisa realizada por Malaquias et. al. (2012) que avaliou a estrutura e a adequação dos 42 jogos catalogados no período de 2008 a 2011. Nesta pesquisa contatou que o maior número de jogos contempla apenas crianças de até 6 anos de idade e que somente $8 \%$ é destinado a adolescentes. Perante essa realidade, percebe-se a importância desse jogo para a educação básica, considerando também que segundo as legislações de EA (Politica Nacional de Educação Ambiental de 1999 e as Diretrizes Curriculares Nacionais de Educação Ambiental de 2012) a educação ambiental deve estar inserida em todos os níveis de ensino de maneira integrada, interdisciplinar e crítica.

\section{Considerações finais}

O lúdico pode ser empregado de muitas maneiras, de forma que possibilitem práticas de ensino de acordo com a grade curricular, abordando temáticas que estimulem o aprendizado, sendo a EA conteúdo obrigatório de todas as disciplinas, esse material didático poderá facilitar essa abordagem de maneira contextualizada e mais crítica.

O jogo quando experimentado no processo de validação pelos professores demonstrou potencializar a participação, a criatividade e a motivação, facilitando a 


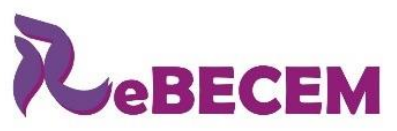

Revista Brasileira de Educação em

Ciências e Educação Matemática

DOI: https://doi.org/10.33238/ReBECEM.2020.v.4.n.2.24234

construção do conhecimento, propiciando o interesse dos educandos para situações socioambientais e, assim, iniciando a formação de cidadãos mais consciente e críticos diante das atuais problemáticas.

Percebeu-se que o jogo é uma ótima ferramenta didática para trabalhar a EA na perspectiva crítica. Ele potencializa o interesse e a motivação dos estudantes, tendo em vista uma melhora no processo de ensino-aprendizagem. O jogo também revelou um grande potencial de trabalho interdisciplinar e transdisciplinar, pois integrou aspectos históricos, sociais e econômicos envoltos nas problemáticas socioambientais, além de promover a interação entre os participantes, o interesse e a criatividade.

\section{Referências}

BARDIN, L. Análise de conteúdo. Lisboa: edições, v. 70, 2004.

BATALLOSO, J. M. Educação e condição humana. In: MORAES, C.M.; ALMEIDA, M.C.; MORIN, E. (org). Os sete saberes necessários a educação do presente. Rio de Janeiro: Editora WAK, 2012. p. 149-184.

BRASIL. Lei n. 9.795, de 27 de abril de 1999. Dispõe sobre a educação ambiental, institui a Política Nacional de Educação Ambiental e dá outras providências. Brasília, DF, abr. 1999. Disponível em: http://www.planalto.gov.br . Acessado em: 28 fev. de 2017.

BRASIL. Resolução n. 2, de 15 de junho de 2012. Estabelece as Diretrizes Curriculares Nacionais para a Educação Ambiental. Diário Oficial da União, Brasília, n. 116, seção 1, p. 70 , 18 jun. 2012.

CARVALHO, I. C. M. Educação Ambiental: A formação do sujeito ecológico. 4. ed. São Paulo: Cortez, 2008.

CORDAZZO, S. T. D.; VIEIRA, M. L. A brincadeira e Suas Implicações nos Processos de Aprendizagem e de Desenvolvimento. Estudo pesquisa psicológica, Rio de Janeiro, v. 7, n. 1, p.89-101, jun. 2007. Disponível em:

http://pepsic.bvsalud.org/scielo.php?script=sci_arttext\&pid=S1808-42812007000100009. Acesso em: 01 mar. de 2019.

COSTA, R. G. A. Um olhar crítico sobre a educação ambiental na formação de professores em uma instituição de ensino superior gaúcha. Revista Eletrônica do Mestrado em Educação Ambiental, Rio Grande. v. 22, p. 177-187, jan./jul. 2009.

GATTI, B. A. Análise das políticas públicas para a formação continuada no Brasil, na última década. Revista Brasileira de Educação, Rio de Janeiro, v. 13, n. 37, p. 57-70, jan./abr. 2008. Disponível em: http://www.scielo.br/pdf/rbedu/v13n37/06.pdf . Acesso em: 11 nov. de 2011.

GOMES, R. R.; FRIEDRICH, M. A. Contribuição dos jogos didáticos na aprendizagem de conteúdos de Ciências e Biologia. In: Encontro Regional Sul de Ensino de Biologia - EREBIO, v, Anais do V Encontro Regional Sul de Ensino de Biologia, Rio de Janeiro: editora, 2001, p. 389-392. 
DOI: https://doi.org/10.33238/ReBECEM.2020.v.4.n.2.24234

JACOBI, P. Educação Ambiental, Cidadania e Sustentabilidade. Cadernos de Pesquisa, São Paulo, n. 118, p. 189-205, mar. 2003.

KATAOKA, M. A.; ANTONIO, M.J.; NEUMAN, P. Contribuições de Edgar Morin para um Curso de Formação Continuada para Professores em Educação Ambiental. Cadernos de Pesquisa: Pensamento Educacional, Curitiba, Número Especial, p.67-84. 2018.

KISHIMOTO, T. M. O jogo e a educação infantil. In: KISHIMOTO, T. M. (org.). Jogo, Brinquedo e a Educação. São Paulo: Cortez, 1996. p. 105-128.

LAYRARGUES, P. P.; LIMA, G. F.C. Mapeando as macro-tendências político-pedagógicas da educação ambiental contemporânea no Brasil. Encontro Pesquisa em Educação Ambiental, Ribeirão Preto, v. 7, p. 2-15, 2011.

MALAQUIAS, J. F.; VASCONCELOS, F.C. W; SILVA, C.S. H. D.; DINIZ, H.D.; SANTIAGO, M. C. lúdico como promoção do aprendizado através dos jogos socioambientais, integrando a educação ambiental formal e não formal. Revista Eletrônica do Mestrado em Educação Ambiental, Rio Grande, v.29, p. 1-16. 2012.

MATTAR, F. N. Pesquisa de marketing. Edição Compacta. 3.ed. São Paulo: Atlas, 2001.

MORIN, E. O método 1: A Natureza da Natureza. 3. ed. Porto Alegre: Sulina, 2013. MORIN, E. Meus Demônios. Rio de Janeiro: Bertrand Brasil, 1997.

OLIVEIRA, L. H. Exemplo de cálculo de Ranking Médio para Likert. Notas de Aula. Metodologia Científica e Técnicas de Pesquisa em Administração. Mestrado em Administração e Desenvolvimento Organizacional. PPGA CNEC/FACECA: Varginha, 2005.

OLIVEIRA, T. L.F.; VARGAS, I. A. Vivências integradas à natureza: por uma educação ambiental que estimule os sentidos. Revista Eletrônica do Mestrado em Educação Ambiental, Rio Grande, v. 22, p. 309-322, 2009.

RIEDER, R.; ZANELATO, E. M.; BRANCHER, J. D. Observação e análise da aplicação de jogos educacionais bidimensionais em um ambiente aberto. In: TALLER INTERNACIONAL DE SOFTWARE EDUCATIVO, 9., 2004, Santiago. Anais... Santiago, 2004. p. 61-66.

RIZZI, L.; HAYDT, R. C. Atividades lúdicas na educação da criança. São Paulo: Editora Ática, 2001.

RIZZI, L.; HAYDT, R. C. C. Atividades lúdicas na educação infantil: subsídios práticos para o trabalho na pré-escola e nas séries iniciam do $1^{\circ}$ grau. 7. ed. São Paulo: Ática, 2007.

SANTAELLA, L. O papel do lúdico na aprendizagem. Revista Teias, Rio de Janeiro, v. 13, n. 30, p. 185-195. 2012.

SANTOS, S. M. P. D. O lúdico na formação do Educador. 6. ed. Petrópolis: Vozes, 1997.

SEPULCRI, B. N.; TRISTÃO, M. F. Formação continuada, pesquisa e narrativas em educação ambiental. Revista Eletrônica do Mestrado em Educação Ambiental, Rio Grande, v. 34, n. 2, p. 190-203. 2017.

SCHILLER, F. Sobre a Educação Estética da Humanidade numa Série de Cartas. Tradução do alemão por Teresa Rodrigues Cadete Lisboa: Imprensa Nacional/Casa da Moeda, 1994. 
DOI: https://doi.org/10.33238/ReBECEM.2020.v.4.n.2.24234

SUANNO, J. H. Práticas inovadoras em educação: uma visão complexa, transdisciplinar e humanística. In: MORAES, M. C.; BATALLOSO NAVAS, J. M. (org.). Complexidade e transdisciplinaridade em educação: teoria e prática docente. Rio de Janeiro: Wak, 2010. p.207-225.

Recebido em: 11 de março de 2020

Aceito em: 20 de julho de 2020 